
\title{
3 Research Square \\ Biosynthesis of Lactones From Diols Mediated by an Artificial Flavin
}

\section{Xiaowang Zhang}

Nanjing Tech University College of Biotechnology and Pharmaceutical Engineering

\section{Zhuotao Tan}

Nanjing Tech University College of Biotechnology and Pharmaceutical Engineering

\section{Chaojian Li}

China Tobacco Jiangsu Industrial Co Ltd

\section{Siyu Qi}

Zhengzhou University

\section{Mengjiao Xu}

Nanjing Tech University College of Biotechnology and Pharmaceutical Engineering

\section{Ming Li}

Nanjing Tech University College of Biotechnology and Pharmaceutical Engineering

\section{Wei Zhuang}

Nanjing Tech University College of Pharmaceutical Science

\section{Dong Liu}

Nanjing Tech University College of Biotechnology and Pharmaceutical Engineering Chenjie Zhu ( $\nabla$ zhucj@njtech.edu.cn )

Nanjing Tech University https://orcid.org/0000-0001-7917-3649

\section{Hanjie Ying}

Nanjing Tech University College of Biotechnology and Pharmaceutical Engineering

\section{Research Article}

Keywords: Lactones, Diols, Cofactor regeneration, Flavin, Biosynthesis

Posted Date: August 13th, 2021

DOl: https://doi.org/10.21203/rs.3.rs-793442/v1

License: (9) (1) This work is licensed under a Creative Commons Attribution 4.0 International License. Read Full License 


\section{Abstract}

Background: Lactones are important compounds in the field of medicine, material and chemical industry. One of the promising accesses to these flexible scaffolds is NAD $(P)^{+}$-dependent alcohol dehydrogenasescatalyzed oxidative lactonization of diols, which relies on the construction of an efficient NAD $(P)^{+}$ regeneration system.

Results: In this study, a novel system combining horse liver alcohol dehydrogenase (HLADH) with the synthetic bridged flavin cofactor was established for biosynthesis of lactones. The reaction conditions of this system were optimized and a variety of lactones including chiral lactones were efficiently obtained from various diols. Compared to the previously reported $N A D(P)^{+}$-regeneration systems, this system showed better regeneration efficiency and product yield. A two-phase system was further applied to solve the problem of product inhibition, and $80 \%$ yield was obtained at the condition of $300 \mathrm{mM}$ substrate.

Conclusions: This study provides an efficient method to synthesis of lactones from diols under mild conditions. We believe this system will be a promising alternative to promote the synthesis of other valuable compounds.

\section{Introduction}

Lactones are key structural motifs in several important chemicals, such as pharmaceuticals, scents and polymers (Fig. 1), due to their excellent physical and biological properties (Schulz et al. 2015; Kim et al. 2021). Over the past few years, various chemical methods for the production of lactones have been extensively studied, such as esterification of hydroxycarboxylic acid (Kauloorkar et al. 2016), lactonization of hydroxy ester under acidic or basic conditions (Marco et al. 2007), lactonization of cyclic ketones by Baeyer-Villiger reaction (Maalouf et al. 2020) and iodolactonization of enoic acid (Nolsøe et al. 2014). However, most of them suffer from disadvantages such as high temperature and pressure, strong acids or bases, rare metal catalysts and stoichiometric amounts of oxidizing agents (Sartori et al. 2021).

The development of biosynthetic methods for lactones has captured the attention of the scientific community over the years due to advantages such as exquisite selectivity, environmental friendliness, and high catalytic efficiency (Schulz et al. 2015; Kim et al. 2021). Several methods for biosynthesis of lactones have been studied (Scheme 1), such as reductive lactonization of ketone ester compounds by ADH from Rhodococcus ruber (ADH-A) (Díaz-Rodríguez et al. 2013) (Scheme 1a), Baeyer-Villiger oxidation of the corresponding cyclic ketones through a monooxygenase (BVMO) (Fink et al. 2013) (Scheme 1b) and lactonization of hydroxy esters precursors by hydrolase (Kamal et al. 2003) (Scheme 1c). Recently, horse liver alcohol dehydrogenase (HLADH)-catalyzed oxidative lactonization of diols was reported (Kara et al. 2013) (Scheme 1d), a laccase-mediator regeneration system was used for the $\mathrm{NAD}^{+}$cycle in the reaction system. However, side reaction of hydrolysis of the generated lactone products was observed as a major limiting factor toward application of this system. 
Recently, we have reported an $\mathrm{NAD}(\mathrm{P})^{+}$regeneration system using synthetic bridged flavin cofactor (SBFC) (Zhu et al. 2016; Tan et al. 2018). In this simple and green system, NAD(P) ${ }^{+}$could be effectively regenerated in vitro or in vivo by using molecular oxygen as terminal electron acceptor. We wonder if this strategy can be applied for the oxidative lactonization reaction. Herein, we established a method for the HLADH-catalyzed transformation of diols into lactones mediated by SBFC (Scheme 1e).

\section{Methods}

\section{Chemicals and strains}

The flavin catalysts SBFC, 3-phenyl-1,5-pentanediol and 3-(4-methoxyphenyl)-1,5-pentanediol was synthesized according to the previous report (Zhu et al. 2016). Detailed methods are described in Additional file 1: Additional methods. Other reagents were ACS reagent grade and used without further purification unless otherwise noted. Catalase were purchased from Aladdin Reagent. Escherichia coli (E.

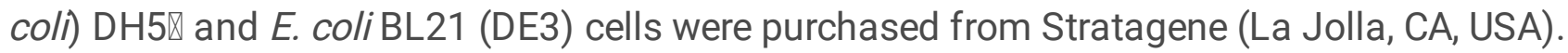

\section{Gene synthesis and construction of recombinant strains}

The genes of alcohol dehydrogenase (ADH) (gene ID: 100034242) from horse liver and myoglobin (Mb) (gene ID: 100054434) from horse heart were both synthesized by GENEWIZ (Genewiz Biotech Co. Ltd. China) with codons optimized for expression in E. coliBL21. The gene of HLADH was further cloned into the Ndel/HindIII sites of pET28a to give pET28a-HLADH plasmid and the gene of Mb was further cloned into the $\mathrm{Ndel} / \mathrm{Xho} /$ sites of pET21a to give pET21a-Mb plasmid.

\section{Enzyme preparation, purification and assay}

Firstly, the recombinant E. coli BL21 were cultured in LB medium (10 mL) supplemented with $50 \mu \mathrm{g} \cdot \mathrm{mL}^{-1}$

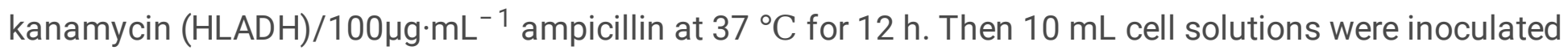
to $400 \mathrm{~mL}$ LB medium supplemented with $50 \mu \mathrm{g} \cdot \mathrm{mL}^{-1}$ kanamycin $/ 100 \mu \mathrm{g} \cdot \mathrm{mL}^{-1}$ ampicillin until the $\mathrm{OD}_{600}$ value increased to $0.6-0.8$. Finally, the cells were induced with $0.1 \mathrm{mM}$ isopropyl- $\beta-\mathrm{d}-1-$

thiogalactopyranoside (IPTG) for $20 \mathrm{~h}$ at $25^{\circ} \mathrm{C}$ and then harvested by centrifugation at $4^{\circ} \mathrm{C}$ for $5 \mathrm{~min}$ at $10000 \mathrm{rpm}$. Cells of pET28a-HLADH and pET21a-Mb were resuspended in PBS buffer ( $50 \mathrm{mM}, \mathrm{pH} 8.0$ ) and disrupted by an Ultrasonic Cell Disruptor (JY92-II, Scientz Biotech. Co. Ltd.). The cell supernatants were purified by a Protein Purifier (GE AKTA Pure). The protein concentration was determined by the Bradford method using bovine serum albumin as standard.

\section{Experimental sections}

HLADH-catalyzed oxidation of diols coupled with SBFC

A mixture of diol $(20 \mathrm{mM}), \mathrm{NAD}^{+}(0.1 \mathrm{mM}), \operatorname{SBFC}(0.05 \mathrm{mM})$ and catalase $(2 \mu \mathrm{M})$ were prepared in $50 \mathrm{mM}$ Tris-HCl buffer ( $\mathrm{pH}$ 8.0). The reactions were initiated by the addition of HLADH solution $\left(0.3 \mathrm{~g} \bullet \mathrm{L}^{-1}\right)$ in a total of $1 \mathrm{~mL}$ of aqueous medium. Reaction mixtures $(1 \mathrm{~mL})$ were shaken at $300 \mathrm{rpm}$ in $2 \mathrm{~mL}$ centrifuge 
tube vessels at $30^{\circ} \mathrm{C}$. Aliquots $(200 \mu \mathrm{L})$ were removed at intervals and mixed with $1000 \mu \mathrm{L}$ of ethyl acetate. The mixture was vortexed for $30 \mathrm{sec}$, followed by centrifugation (12000 rpm, $2 \mathrm{~min}$ ). The organic phase was removed and dried over anhydrous $\mathrm{MgSO}_{4}$, which was further identified by GC-MS.

For different concentrations of substrate catalyzed by HLADH-SBFC system

A mixture of 1,4-butanediol (1,4-BD) $(10 \mathrm{mM}-250 \mathrm{mM}), \mathrm{NAD}^{+}(0.1 \mathrm{mM}), \operatorname{SBFC}(0.05 \mathrm{mM})$ and catalase $(2 \mu \mathrm{M})$ were prepared in $50 \mathrm{mM}$ Tris- $\mathrm{HCl}$ buffer $(\mathrm{pH} 8.0)$. The reactions were initiated by the addition of HLADH solution $\left(0.3 \mathrm{~g} \cdot \mathrm{L}^{-1}\right)$ in a total of $1 \mathrm{~mL}$ of aqueous medium. Reaction mixtures $(1 \mathrm{~mL})$ were shaken at $300 \mathrm{rpm}$ in $2 \mathrm{~mL}$ centrifuge tube vessels at $30^{\circ} \mathrm{C}$. The sample processing method is carried out as described above.

HLADH-catalyzed oxidation of 1,4-BD coupled with Mb

A mixture of 1,4-BD $(250 \mathrm{mM}), \mathrm{NAD}^{+}(0.1 \mathrm{mM}), \mathrm{Mb}\left(0.2 \mathrm{~g} \cdot \mathrm{L}^{-1}\right)$ and $\mathrm{H}_{2} \mathrm{O}_{2}(500 \mathrm{mM})$ were prepared in 50 $\mathrm{mM}$ Tris- $\mathrm{HCl}$ buffer $(\mathrm{pH} 8.0)$. The reactions were initiated by the addition of HLADH solution $\left(0.3 \mathrm{~g} \cdot \mathrm{L}^{-1}\right)$ in a total of $1 \mathrm{~mL}$ of aqueous medium. Reaction mixtures $(1 \mathrm{~mL})$ were shaken at $300 \mathrm{rpm}$ in $2 \mathrm{~mL}$ centrifuge tube vessels at $30^{\circ} \mathrm{C}$. The sample processing method is carried out as described above.

HLADH-catalyzed oxidation of 1,4-BD in a two-liquid phase system (2LPS)

A mixture of 1,4-BD (100 mM-300 mM), NAD $(0.1 \mathrm{mM}), \operatorname{SBFC}(0.05 \mathrm{mM})$ and catalase $(2 \mu \mathrm{M})$ was prepared in $50 \mathrm{mM}$ Tris-HCl buffer $(\mathrm{pH} \mathrm{8.0)}$. The reactions were initiated by the addition of HLADH solution $\left(0.3 \mathrm{~g} \bullet \mathrm{L}^{-1}\right)$ in a total of $1 \mathrm{~mL}$ of aqueous medium. After addition of the enzymes, $5 \mathrm{~mL}$ of organic solvent was immediately added to the aqueous reaction medium. The reaction mixtures $(6 \mathrm{~mL})$ were shaken at $300 \mathrm{rpm}$ in $10 \mathrm{~mL}$ falcon tubes at $30^{\circ} \mathrm{C}$. Aliquots $(25 \mu \mathrm{L})$ were removed from the clearly separated organic phase at intervals and mixed with $225 \mu \mathrm{L}$ of ethyl acetate. The mixture was vortexed for $20 \mathrm{sec}$ and dried over anhydrous $\mathrm{MgSO}_{4}$, which was further identified by GC-MS.

\section{Analytical method}

Characterization of all substrates and products was analyzed by GC-MS instrument (Agilent 7890B GC/5977A MS detector) which was equipped with a HP-5 MS capillary column $(30 \mathrm{~m} \times 0.25 \mathrm{~mm} \times 0.25$ $\mu \mathrm{m}$ ). The injection volume was $1.0 \mu \mathrm{L}$ with an autosampler and helium was used as a carrier gas with column flow rate of $1.5 \mathrm{~mL} \cdot \mathrm{min}^{-1}$. The electron ionization (EI) mass spectra in the range of 35-700 $(\mathrm{m} / \mathrm{z})$ were recorded in the full-scan mode. The detected compounds were identified based on NIST database. The products except 4-phenyltetrahydro-2H-pyran-2-one (8b) and 4-(4-methoxyphenyl) tetrahydro-2H-pyran-2-one (9b) are quantified by gas chromatography. GC was equipped with a HPINNOWAX capillary column $(60 \mathrm{~m} \times 0.25 \mathrm{~mm} \times 0.5 \mu \mathrm{m})$ or a modified $\beta$-cyclodextrin capillary column CPChirasil DEX CB $(25 \mathrm{~m} \times 0.25 \mathrm{~mm} \times 0.25 \mu \mathrm{m})$ for chiral separation. The products $8 \mathrm{~b}$ and $9 \mathrm{~b}$ were analyzed by using HPLC (Agilent 1200) which was equipped with a Chiralcel AS-H capillary column (250 $\mathrm{mm} \times 4.6 \mathrm{~mm} \times 5 \mu \mathrm{m}$ ). Detailed methods are described in Additional file 1: Additional methods. 


\section{Results And Discussion}

In the first set of experiments, 1,4-BD was used as the model substrate. As shown in Fig. 2a, >99\% yield of butyrolactone was obtained in $6 \mathrm{~h}$, revealing that this HLADH-SBFC system-catalyzed oxidative lactonization was successfully constructed. Time-selectivity plots of 1,4-BD conversion showed that lactol was generated during the reaction and disappeared at the end of the reaction (Fig. 2b). It indicated that there were three steps in the oxidative lactonization of 1,4-BD to butyrolactone. HLADH firstly oxidized 1,4-BD to an unstable hydroxy aldehyde intermediate, which then spontaneous cyclized to the corresponding intermediate lactol, the subsequent further oxidation of lactol gave access to the stable final product lactone (Scheme 1). The control experiments proved that in the absence of HLADH, NAD ${ }^{+}$or SBFC, no significant conversion of 1,4-BD was detected.

Optimization of the whole system was further investigated. Firstly, considering the cost of cofactor NAD ${ }^{+}$, we explored if decreasing the amount of $\mathrm{NAD}^{+}$could affect the efficiency of the reaction. It was found that there was no effect on the conversion of 1,4-BD when decreased the amount of NAD from $0.5 \mathrm{mM}$ to $0.1 \mathrm{mM}$ (Table 1, entries 1 and 2). Further decreasing the amount to $0.05 \mathrm{mM}$, it took twice as long as the original catalytic time to finish this reaction (Table 1, entry 3 ). With regard to the dosage of SBFC, it was possible to decrease the amount of SBFC to as low as $0.05 \mathrm{mM}$ without a loss in catalytic efficiency (Table 1, entry 4). Further reducing the amount of SBFC to $0.01 \mathrm{mM}$ led to a significant decrease of conversion (Table 1, entry 5). The influence of $\mathrm{pH}$ and temperature on the reaction were further explored, the results showed HLADH-SBFC system exhibited high stability and activity over broad pH (7.0-10.0) and temperature $\left(20^{\circ} \mathrm{C}\right.$ to $50^{\circ} \mathrm{C}$ ) (Additional file 1: Figure S1 and S2). Finally, $\mathrm{pH} 8.0$ and $30{ }^{\circ} \mathrm{C}$ were selected as the optical conditions.

Table 1. HLADH-SBFC system-catalyzed oxidative lactonization of 1,4-butanediol

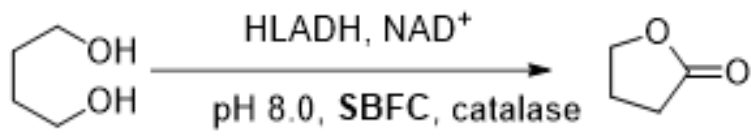

\begin{tabular}{cccccccc}
\hline Entry & $\begin{array}{c}1,4-B D \\
{[\mathrm{mM}]}\end{array}$ & $\begin{array}{c}\text { HLADH } \\
{[\mathrm{mg} / \mathrm{mL}]}\end{array}$ & $\begin{array}{c}\mathrm{NAD}^{+} \\
{[\mathrm{mM}]}\end{array}$ & $\begin{array}{c}\text { SBFC } \\
{[\mathrm{mM}]}\end{array}$ & $\begin{array}{c}\text { Time } \\
{[\mathrm{h}]}\end{array}$ & $\begin{array}{c}\text { Conversion }^{[\mathrm{b}]} \\
{[\%]}\end{array}$ & $\begin{array}{c}\text { Yield[c] }^{2} \\
{[\%]}\end{array}$ \\
\hline $1^{[\mathrm{a}]}$ & 20 & 0.3 & 0.5 & 0.1 & 6 & 100 & $>99$ \\
2 & 20 & 0.3 & 0.1 & 0.1 & 6 & 100 & $>99$ \\
3 & 20 & 0.3 & 0.05 & 0.1 & 12 & 100 & $>99$ \\
4 & 20 & 0.3 & 0.1 & 0.05 & 6 & 100 & $>99$ \\
5 & 20 & 0.3 & 0.1 & 0.01 & 12 & 60 & 60 \\
\hline
\end{tabular}

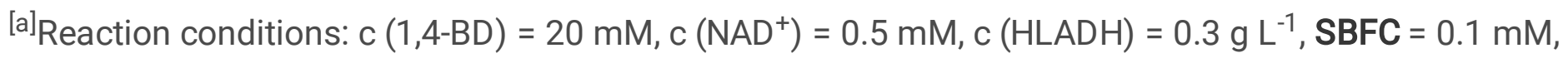
Catalase $=2 \mu \mathrm{M}$, buffer: Tris- $\mathrm{HCl}(50 \mathrm{mM}, \mathrm{pH} 8.0), \mathrm{T}=30^{\circ} \mathrm{C} .{ }^{[b]}$ Conversion was determined by GC analysis; ${ }^{[c]}$ Yield was determined by GC analysis. 
With the aim to develop and define the scope and limitation of the present method, the present catalytic system was then extended for the oxidation of a wide range of diols. Excellent chemoselectivity was observed under the present system, the formation of dialdehydes or over-oxidation to carboxylic acid was not found during the reaction. Although a small amount of lactol intermediates were detected during the reaction, but all disappeared at the end of the reactions except for $\mathbf{5 a}$ (vide infra). For saturated straight chain diols, the yield of lactone decreases with the extension of the carbon chain (entries 1-3). 1,4-BD (1a) and 1,5-pentanediol (2a) underwent smooth oxidation to the corresponding lactone in excellent yield (entries 1 and 2). However, the transformation of 1,6-hexanediol (3a) into $\varepsilon$-caprolactone was much more sluggish, reaching only $50 \%$ yield after prolonged reaction time (entry 3 ), which probably caused by the fact that the lactol formation is rate-determining step, rather than the poor activity of HLADH toward the 7-membered lactol, due to the fact that lactol accumulation was not observed during the reaction. In addition, unsaturated straight chain diols showed less reactive than saturated ones (entry 4 vs. entry 1). It is worth noting that the substrate configuration has a great influence on the activity of the reaction. Cis-2butene-1,4-diol (4a) was efficiently converted into the corresponding lactone (4b) in excellent yield (95\%) in $12 \mathrm{~h}$, whereas only trace amount of product was obtained by using trans-2-butene-1,4-diol (5a) as the substrate (entries $4 v s$. 5). This result could be explained by the steric hindrance effect during the transformation of hydroxyl aldehyde into lactol, due to hydroxyl aldehyde accumulation was observed during the reaction (Additional file 1: Figure S6). For cycloalkane diol, although its reactivity is lower than that of chain diols, satisfactory yield could also be obtained after prolonged reaction time (entry 6), which showed much higher efficiency compared to the previous report using Ru complex as the regeneration catalyst (72 h vs. $116 \mathrm{~h}$ ) (Gerhard et al. 1997), due to the fact that TOF $\left(21.9 \mathrm{~min}^{-1}\right)$ of SBFC-catalyzed NADH oxidation was higher than that of Ru complex system (TOF $3.4 \mathrm{~min}^{-1}$ ) (Zhu et al. 2016),thus indicating superior catalytic activity with the synthetic flavin analogue.

Chiral lactones are important building blocks for the chemical synthesis (Miyaoka et al. 2011; Lehr et al. 2012), the oxidative desymmetrization of prochiral diols 7a-9a were then examined to assess the feasibility of the present catalytic system for the construction of chiral lactones. Although high yields (> 95\%) were achieved in all three reactions, the reaction time and optical purity of the products varied greatly. The transformation of 7a was completed within $6 \mathrm{~h}$, which was much faster than that of $\mathbf{8 a}$ and $9 a$ (36 $h$ and $72 h$ ) (entries 7-9), which suggested that the substrate with larger substituent group binds less efficiently in the active site of enzyme pocket. In terms of product chirality, this catalytic system proceeded with stereoselectivity towards the $(S)$-enantiomer, which is in accordance with the rule of preferred stereoselectivity of HLADH (Díaz-Rodríguez et al. 2014; Kara et al. 2013). For the reaction of 7a and $\mathbf{8 a}$, as high as $>95 \%$ ee was observed in the present catalytic system (Additional file 1: Figure S11 and S12). In particular, a significant improvement in the enantioselectivity of $\mathbf{8 b}$ was achieved compared to the previously reported HLADH-lactate dehydrogenase (LDH) system (95\% ee vs. $74 \%$ ee) (DíazRodríguez et al. 2014). However, the introduction of methoxy group in the aromatic ring at the para position led to a significant decline in the ee (entry 8 vs. 9), which could owe to the additional interactions between methoxy group and residues in the HLADH active site. Based on the above results, we can hypothesize that the enantioselectivity of this process is affected not only by the size of the substituent 
but also by its interaction with enzyme. Further investigations clarifying these issues are currently underway. Finally, reaction of diethylene glycol (10a) and diethanolamine (11a) were tested for the reaction, however, no conversion was detected due to the poor recognition of HLADH (entries 10 and 11), despite their structural analogy with $\mathbf{2 a}$.

Table 2. HLADH-SBFC- catalyzed oxidative lactonization reactions ${ }^{[a]}$

Entry


${ }^{\left[a^{2}\right.}$ Reaction conditions: $\mathrm{c}$ (diols) $=20 \mathrm{mM}, \mathrm{c}\left(\mathrm{NAD}^{+}\right)=0.1 \mathrm{mM}, \mathrm{c}(\mathrm{HLADH})=0.3 \mathrm{~g} \cdot \mathrm{L}^{-1}, \mathrm{c}(\mathrm{SBFC})=0.05 \mathrm{mM}$, Catalase $=2 \mu \mathrm{M}$, buffer: Tris- $\mathrm{HCl}(50 \mathrm{mM}, \mathrm{pH} 8.0), \mathrm{T}=30^{\circ} \mathrm{C}$; ${ }^{[b]}$ Yield were determined by GC and HPLC; ${ }^{[\mathrm{c}]}$ The ee values of lactones were determined by chiral HPLC and GC.

To assess the possibility of the present catalytic system to more preparative interesting values, the lactonization of 1,4-BD at different concentrations (10-250 mM) were performed under the optimal conditions. As shown in the Fig. 3 , reasonable yield ( $80 \%$ ) could be obtained when the substrate concentration was increased to $100 \mathrm{mM}$ after prolonged reaction time. Further increasing the concentration to $250 \mathrm{mM}$ led to a dramatical decrease in yield (43\%). Actually, this phenomenon was also observed in other catalytic systems. We then compared the present SBFC system with Myoglobin (Mb) system (Jia et al. 2019) and laccase-mediator system (LMS) (Kara et al. 2013) for the oxidative lactonization of 1,4-BD under the condition of $250 \mathrm{mM}$ substrate concentration. As shown in Table 3, only ca. $10 \%$ yield was obtained by using $\mathrm{Mb}$ regeneration system after prolonged reaction time (entry 2 ), this is not only due to the low regeneration efficiency of $\mathrm{Mb}$ system, but also due to the inhibition of excessive hydrogen peroxide (Liao et al. 2021). In addition, low yield of $38 \%$ was also observed for the LMS regeneration system even under efficient $\mathrm{O}_{2}$-intake conditions (entry 3 ). According to the previous study (Kara et al. 2013), a significant acidification of the reaction mixture was observed for LMS regeneration system, indicating that hydrolysis of $y$-butyrolactone occurred during the reaction. This side reaction of hydrolysis was further increased with the increase of laccase dosage, suggesting that the existence of laccase might promote the hydrolysis side reaction. It is worth noting that, compared with LMS regeneration system, hydrolysis of $\mathrm{Y}$-butyrolactone was not found in the present SBFC regeneration system, no hydroxy acid formation was detected during the reaction, and the $\mathrm{pH}$ of the reaction mixture remained roughly the same even after 72 hours.

Table 3. HLADH catalyzed oxidative lactonization reaction mediated by different regeneration systems

\begin{tabular}{|llll|}
\hline Entry & Regeneration system & $\begin{array}{l}\text { Yield } \\
{[\%]}\end{array}$ & $\begin{array}{l}\text { Time } \\
{[\mathrm{h}]}\end{array}$ \\
\hline $1^{[\mathrm{a}]}$ & SBFC, $\mathrm{O}_{2}$, catalase & 43 & 48 \\
$2^{[\mathrm{b}]}$ & $\mathrm{Mb}, \mathrm{H}_{2} \mathrm{O}_{2}$ & 10 & 72 \\
$3^{[\mathrm{c}]}$ & Laccase, ABTS, $\mathrm{O}_{2}$ & 38 & 72 \\
\hline
\end{tabular}

[a] for SBFC regeneration method, SBFC $(0.05 \mathrm{mM})$ and catalase $(0.2 \mu \mathrm{M})$ were supplemented; [b] for $\mathrm{Mb}$ regeneration method, $\mathrm{Mb}\left(0.2 \mathrm{~g} \cdot \mathrm{L}^{-1}\right)$ and $\mathrm{H}_{2} \mathrm{O}_{2}(500 \mathrm{mM})$ were supplemented; [c] The data come from literature (Kara et al. 2013). Standard reaction conditions: $\mathrm{c}(1,4-\mathrm{BD})=250 \mathrm{mM}, \mathrm{c}\left(\mathrm{NAD}^{+}\right)=0.1 \mathrm{mM}, \mathrm{c}$ $(\mathrm{HLADH})=0.3 \mathrm{~g} \cdot \mathrm{L}^{-1}$, buffer: $\mathrm{Tris}-\mathrm{HCl}(50 \mathrm{mM}, \mathrm{pH} 8.0), \mathrm{T}=30^{\circ} \mathrm{C}$.

Excluding the factor of hydrolysis side reaction, we attribute the low yield at high substrate concentration to the product inhibition. A further attempt by using a two-liquid phase system for the in situ extraction of 
the generated lactone into an organic phase was tried to circumvent this limitation. Five organic solvents which have been reported to have negligible influence on HLADH activity were tested for this reaction (Villela Filho et al. 2003). As shown in the Fig. 4a, ethyl acetate exhibited the best extraction efficiency (Additional file 1: Table S1), however, only $30 \%$ of yield was observed after the reaction, which probably due to its low log $P$ value (0.7) (Villela Filho et al. 2003). Among the selected solvents, toluene gave the highest $\log P$ value (2.3) and obtained the highest yield (94\%). Thus, a two-liquid phase system of toluene- $\mathrm{H}_{2} \mathrm{O}$ was used for the subsequent experiments. As shown in Fig. 4b, this approach was successfully improved the substrate loading issue. A satisfactory of $83 \%$ yield was achieved even at a substrate concentration of $300 \mathrm{mM}$ (Fig. 4b), which is the highest level reported in the literature to date. Particularly worth mentioning is SBFC has excellent water solubility due to its organic salt property, which makes it difficult to be extracted into the organic solvent phase (Additional file 1: Table S1), thus avoiding hindering the reaction. This feature makes it extremely suitable for the present two-phase system.

\section{Conclusion}

In conclusion, an efficient biocatalytic oxidation system for the synthesis of lactones from diols mediated by SBFC was developed, broad substrate scope, mild reaction conditions, good reaction selectivity, and satisfactory production yield were observed for the present system. Valuable chiral lactones were also can obtained with high efficiency. Furthermore, this system showed good organic solvent compatibility and a two-liquid phase system was successfully used to alleviate the lactone inhibition issue, leading to high product yield (83\%) at substrate concentrations of $300 \mathrm{mM}$ by using toluene as the extracting solvent. We believe this method offers an ideal strategy for more related biocatalytic oxidation systems.

\section{Abbreviations}

HLADH: Horse liver alcohol dehydrogenase; IPTG: Isopropyl $\beta$-D-1-thiogalactopyranoside; HPLC: Highperformance liquid chromatography; SDS-PAGE: Sodium dodecyl sulfate polyacrylamide gel electrophoresis; SBFC: Synthetic bridged flavin cofactor; Mb: Myoglobin; 2LPS: Two-liquid phase system; GC-MS: Gas chromatography - mass spectrometry; GC: Gas chromatography; 1,4-BD: 1,4-butanediol; LDH: Lactate dehydrogenase; LMS: Laccase mediated system.

\section{Declarations}

\section{Ethics approval and consent to participate}

Not applicable.

\section{Consent for publication}

Not applicable.

\section{Availability of data and materials}


They are included within the article and its Additional files.

\section{Competing interests}

The authors declare no competing financial interests.

\section{Funding}

We thank the financial support by the National Key Research and Development Program of China (Grant No.: 2019YFD1101202); Jiangsu Province Natural Science Foundation for Distinguished Young Scholars (Grant No.: BK20190035); Program of National Natural Science Foundation of China (Grant No.:21776132, 21878142); Six talent peaks project in Jiangsu Province (SWYY-045); Jiangsu Province Natural Science Foundation for Youth (Grant No.: BK20200685); China Postdoctoral Science Foundation Funded Project (Grant No.: 2019M660113).

\section{Authors' contributions}

$\mathrm{CZ}$ and $\mathrm{ZT}$ conceived the research. XW and MX designed the experiments. SQ and XW conducted the experiments. ML participated in helping XW to complete the relevant experiments. $\mathrm{HY}, \mathrm{CL}$ and $\mathrm{WZ}$ gave some guidance to the experiments. XZ finalized the manuscript with assistance from DL. All authors read and approved the final manuscript.

\section{Acknowledgements}

Not applicable.

\section{References}

1. Delgove MAF, Elford MT, Bernaerts KV, Wildeman SMA (2018) Toward upscaled biocatalytic preparation of lactone building blocks for polymer applications. Org Process Res Dev 22:803-812

2. Díaz-Rodríguez A, Borzęcka W, Lavandera I, Gotor V (2013) Stereodivergent preparation of valuable Yor $\delta$-hydroxy esters and lactones through one-pot cascade or tandem chemoenzymatic protocols. ACS Catal 4:386-393

3. Díaz-Rodríguez A, Iglesias-Fernández J, Rovira C, Gotor-Fernández V (2014) Enantioselective preparation of $\delta$-valerolactones with horse liver alcohol dehydrogenase. ChemCatChem 6:977-980

4. Fink MJ, Schön M, Rudroff F, Schnürch M, Mihovilovic MD (2013) Single operation stereoselective synthesis of aerangis lactones: combining continuous flow hydrogenation and biocatalysts in a chemoenzymatic sequence. ChemCatChem 5:724-727

5. Gerhard H, Burhanshah L, Guillermo M, James HPU, Eberhard S (1997) Efficient in-situ redox catalytic $\mathrm{NAD}(\mathrm{P})^{+}$regeneration in enzymatic synthesis using transition-metal complexes of I, I0phenanthroline-5,6-dione and its $\mathrm{N}$-monomethylated derivative as catalysts. Liebigs Ann Recl 17:2289-2296 
6. Jia HY, Zong MH, Zheng GW, Li N (2019) Myoglobin-catalyzed efficient in situ regeneration of $\operatorname{NAD}(P)^{+}$and their synthetic biomimetic for dehydrogenase-mediated oxidations. ACS Catal 9:21962202

7. Kamal A, Sandbhor M, Shaik AA (2003) Application of a one-pot lipase resolution strategy for the synthesis of chiral $Y$ - and $\delta$-lactones. Tetrahedron: Asymmetry 14:1575-1580

8. Kara S, Spickermann D, Schrittwieser JH, Weckbecker A, Leggewie C, Arends IWCE, Hollmann F (2013) Access to lactone building blocks via horse liver alcohol dehydrogenase-catalyzed oxidative lactonization. ACS Catal 3:2436-2439

9. Kauloorkar SV, Kumar P (2016) Total synthesis of (-)-(6R,11R,14S)-colletallol via proline catalyzed aaminoxylation and yamaguchi macrolactonization. RSC Adv 6:63607-63612

10. Kim Y, Sengupta S, Sim T (2021) Natural and synthetic lactones possessing antitumor activities. Int J Mol Sci 22:1052-1118

11. Lehr $\mathrm{K}$, Fürstner $\mathrm{A}$ (2012) An efficient route to the musk odorant $(R, Z)-5$-muscenone via base-metalcatalysis. Tetrahedron 68:7695-7700

12. Liao HX, Jia HR, Dai JR, Zong MH, Li N (2021) Bioinspired cooperative photobiocatalytic regeneration of oxidized nicotinamide cofactors for catalytic oxidations. ChemSusChem 14:16871691

13. Marco JA, Carda M, Murga J, Falomir E (2007) Stereoselective syntheses of naturally occurring 5,6dihydropyran-2-ones. Tetrahedron 63:2929-2958

14. Maalouf JH, Jin K, Yang D, Limaye AM, Manthiram K (2020) Kinetic analysis of electrochemical lactonization of ketones using water as the oxygen atom source. ACS Catal 10:5750-5756

15. Martin C, Trajkovic M, Fraaije MW (2020) Production of hydroxy acids: selective double oxidation of diols by flavoprotein alcohol oxidase. Angew Chem Int Ed 59:4869-4872

16. Miyaoka H, Okubo Y, Muroi M, Mitome H, Kawashima E (2011) A formal synthesis of antimalarial diterpenoid 7,20-diisocyanoadociane. Chem Lett 40:246-247

17. Nolsøe JMJ, Hansen TV (2014) Asymmetric iodolactonization: an evolutionary account. Eur J Org Chem 2014:3051-306

18. Puetz H, Puchl'ová E, Vranková K, Hollmann F (2020) Biocatalytic oxidation of alcohols. Catalysts 10:952-981

19. Sartori SK, Diaz MAN, Diaz-Muñoz G (2021) Lactones: classification, synthesis, biological activities, and industrial applications. Tetrahedron 84:132001-123039

20. Schulz S, Hotling S (2015) The use of the lactone motif in chemical communication. Nat Prod Rep 32:1042-1066

21. Tan Z, Zhu C, Fu J, Zhang X, Li M, Zhuang W, Ying H (2018) Regulating cofactor balance in vivo with a synthetic flavin analogue. Angew Chem Int Ed 57:16464-16468

22. Villela Filho M, Stillger T, Muller M, Liese A, Wandrey C (2003) Is log $P$ a convenient criterion to guide the choice of solvents for biphasic enzymatic reactions? Angew Chem Int Ed 42:2993-2996 
23. Winkler CK, Schrittwieser JH, Kroutil W (2021) Power of biocatalysis for organic synthesis. ACS Cent Sci 7:55-71

24. Zhu C, Li Q, Pu L, Tan Z, Guo K, Ying H, Ouyang P (2016) Nonenzymatic and metal-free organocatalysis for in situ regeneration of oxidized cofactors by activation and reduction of molecular oxygen. ACS Catal 6:4989-4994

\section{Figures}

Typical scents containing lactone structure<smiles>CNCC1CCC(=O)O1</smiles>

Gamma-lactone

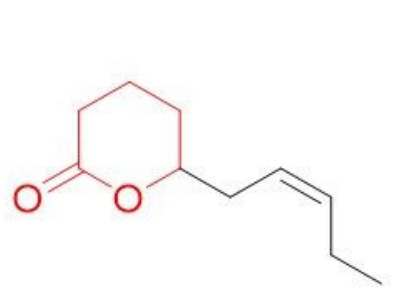

(Z)-7-decen-5-olide
Typical polymers derived from lactone structure<smiles>[R]C(COC)CC(C)=O</smiles><smiles></smiles>

Polycaprolactone

Typical pharmaceuticals containing lactone structure<smiles>CC(=O)CC(c1ccccc1)c1c(O[N+]([O-])O)c2ccccc2oc1=O</smiles>

Warfarin<smiles>CCCCC/C=C\[C@H]1CC=CC(=O)O1</smiles>

Argentilactone

\section{Figure 1}

Types of compounds derived from lactone structure. 

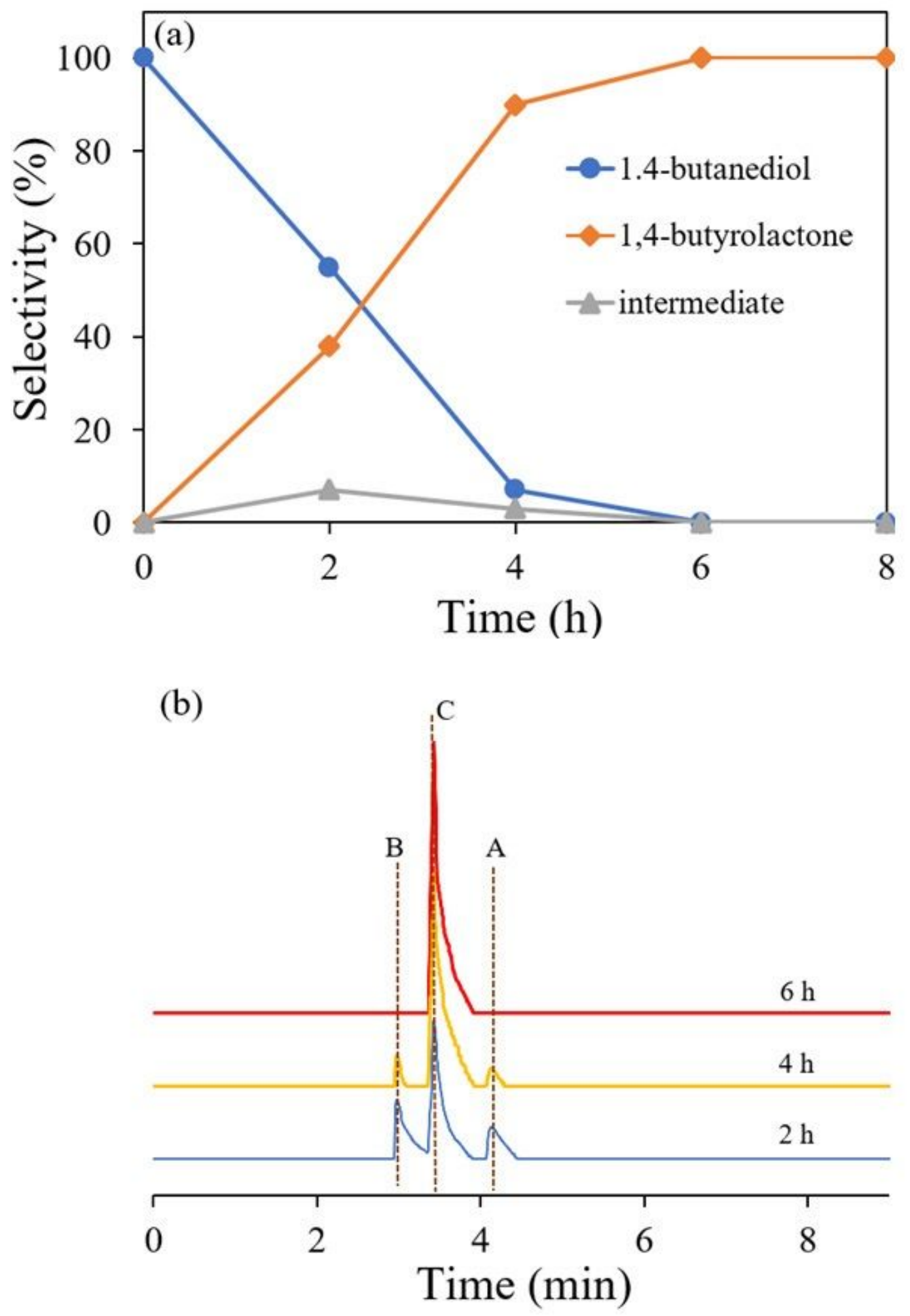

Figure 2

a) Time-selectivity plots of HLADH-catalyzed oxidation of 1,4-BD. c (1,4-BD) $=20 \mathrm{mM}, \mathrm{c}(\mathrm{NAD}+)=0.5 \mathrm{mM}$, $\mathrm{c}(\mathrm{HLADH})=0.3 \mathrm{~g} \mathrm{~L}-1, \mathrm{SBFC}=0.1 \mathrm{mM}$, Catalase $=2 \mu \mathrm{M}$, buffer: Tris-HCl $\left.(50 \mathrm{mM}, \mathrm{pH} 8.0), \mathrm{T}=30^{\circ} \mathrm{C} . \mathrm{b}\right)$ The results of reactions after $2 \mathrm{~h}, 4 \mathrm{~h}$ and $6 \mathrm{~h}$ detected by GC-MS. Peak A: 1,4-BD; Peak B: lactol; Peak C: butyrolactone. 


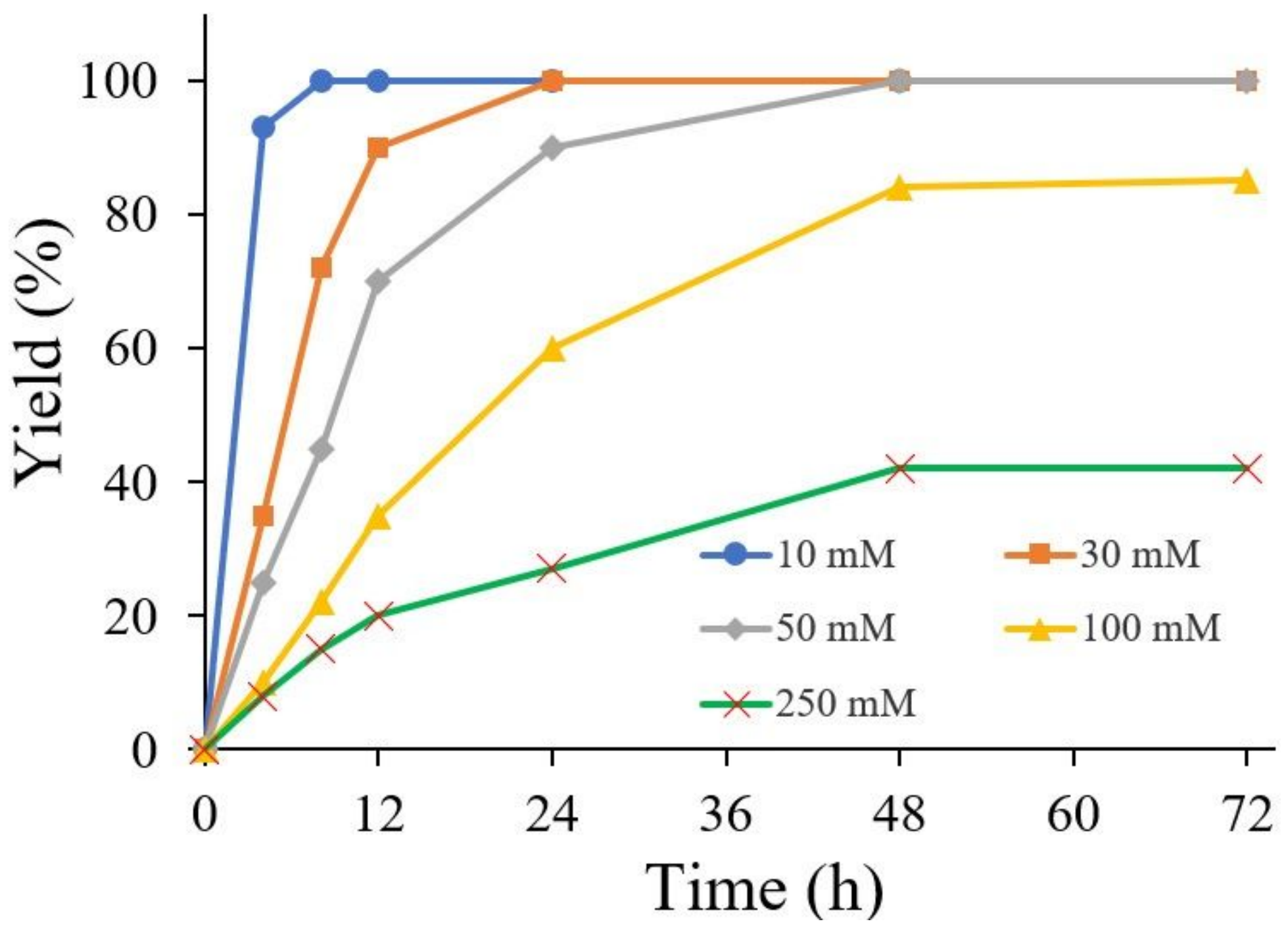

Figure 3

HLADH-catalyzed oxidation lactonization of 1,4-BD at different substrate concentrations. Reaction conditions: $\mathrm{c}(\mathrm{NAD}+)=0.1 \mathrm{mM}, \mathrm{c}(\mathrm{HLADH})=0.3 \mathrm{~g} \bullet \mathrm{L}-1, \mathrm{SBFC}=0.05 \mathrm{mM}$, Catalase $=2 \mu \mathrm{M}$, buffer: Tris $-\mathrm{HCl}$ $(50 \mathrm{mM}, \mathrm{pH} 8.0), \mathrm{T}=30^{\circ} \mathrm{C}$. Yields are average values of duplicates. 

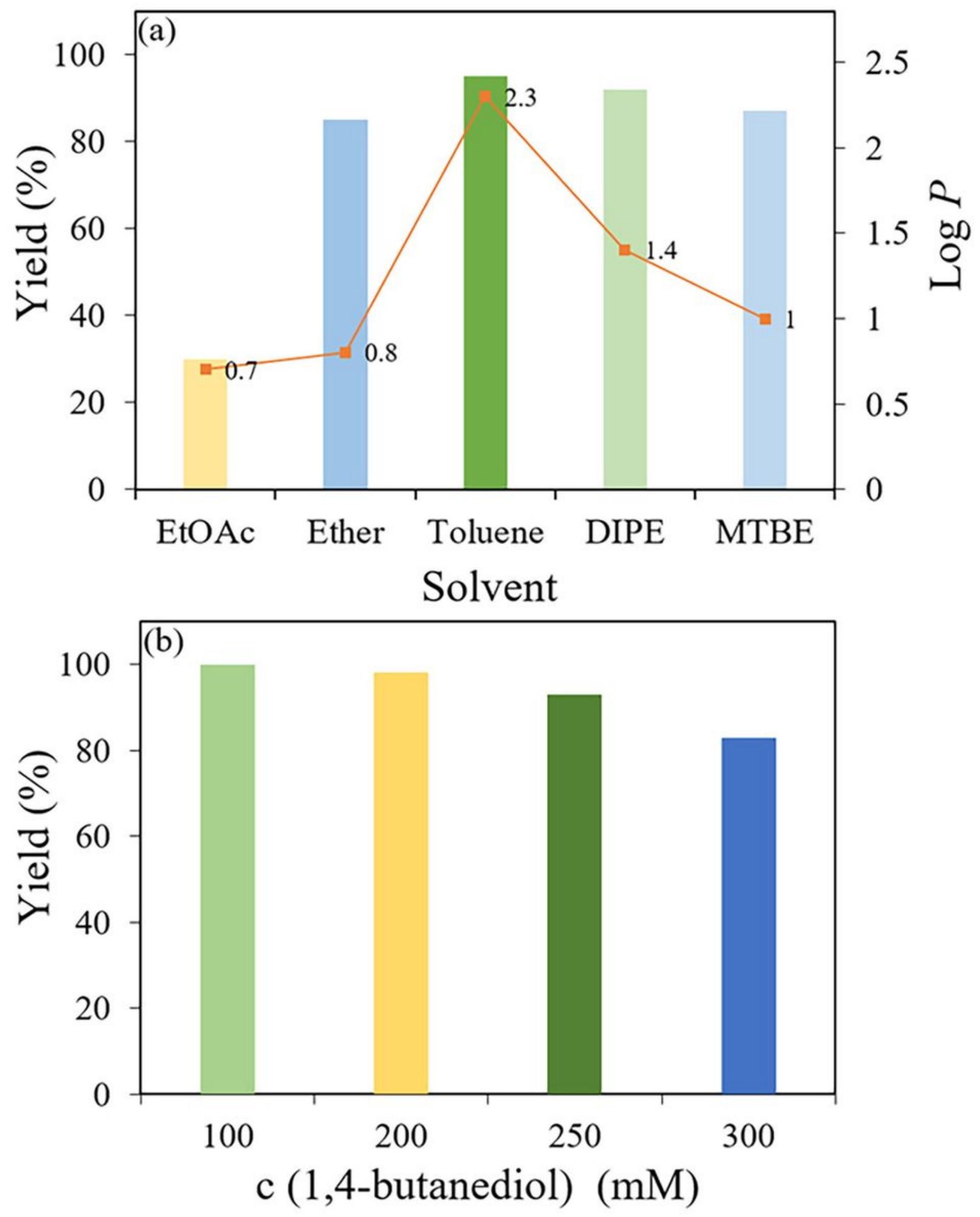

Figure 4

HLADH-catalyzed oxidation lactonization of 1,4-BD in a two-liquid phase system (2LPS). Standard reaction conditions (aqueous, $1 \mathrm{~mL}): \mathrm{c}(\mathrm{HLADH})=0.3 \mathrm{~g} \cdot \mathrm{L}-1, \mathrm{c}(\mathrm{NAD}+)=0.1 \mathrm{mM}, \mathrm{SBFC}=0.05 \mathrm{mM}$, Catalase $=2 \mu \mathrm{M}$, buffer: Tris- $\mathrm{HCl}(50 \mathrm{mM}, \mathrm{pH} 8.0), \mathrm{T}=30^{\circ} \mathrm{C}$. a) $\mathrm{c}(1,4-\mathrm{BD})=100 \mathrm{mM}$, and in different organic phase. Detection after $24 \mathrm{~h}$. EtOAc: ethyl acetate, DIPE: diisopropyl ether, MTBE: tert-butyl methyl 
ether. b) At different substrate concentrations; organic phase: toluene $(5 \mathrm{~mL}), \mathrm{V}$ organic/V aqueous $=5$. Detection after $48 \mathrm{~h}$. Yields are average values of duplicates.

\section{Supplementary Files}

This is a list of supplementary files associated with this preprint. Click to download.

- Scheme1.jpg

- GraphicalAbstract.jpg

- SupplementaryMaterial.doc 